\title{
Free Flow of Information and Knowledge and Use of IT in a Conservative Community: The Case of the Ultra-Orthodox in Israel
}

\author{
Moshe Yitzhaki \\ Department of Information Studies, Bar-Ilan University, \\ Ramat-Gan, Israel \\ yitzhm@mail.biu.ac.il
}

\begin{abstract}
The free flow of unfiltered information, as facilitated by current IT, poses great challenges for a conservative community that strives to retain its members, and especially its youngsters, within a traditional lifestyle. The study explores the ways by which the Israeli ultra-orthodox community, a conservative minority one, upholding a unique subculture, copes with the challenges of unrestricted information flow in a developed country like Israel, which largely embraces the latest IT innovations.
\end{abstract}

Keywords: ultra-orthodox community, Israel, information flow, barriers, conservative societies, Internet filtering

\section{Introduction}

This descriptive paper shares experienceabout how IT penetrates in closed groups, which possess "strong" cultures, preventing their members of using it, as in the orthodox Jewish communities.To a great extent this paper can be considered as an empirical study of what Grandon Gill's 2013 paper" Culture, complexity, and informing" argues. We would like to share our local experience in dealing with the"digital divide" when a group strongly resists to accept technology. Such groups exist in many societies, although not alwayswith the level of resistance as the ultraorthodox Jewish community described below.

Generally speaking, two distinct religious groups can be distinguished among the orthodox Jewish population world-wide: modern orthodox and ultra-orthodox. The modern orthodox are usually much more open to the modern world, combine'secular' general and academic studies in their educational system, and are more involved in the surrounding 'secular' world. The ultra-orthodox groups, on the contrary, are less open to the modern world, strongly adhering to traditions and customs.

Understandably, the free flow of unfiltered information, as facilitated by current IT, poses great challenges for a conservative community, which strives to retain its members, and especially its youngsters, within a traditional lifestyle.

\section{Objective of the Study}

The aim of our study was to explore the ways by which a conservative minority community upholding a unique subculture copes with the challenges of unrestricted information flow in a developed country whichlargely embraces the latest IT innovations. Our current analysis is limited 
to the ultra-orthodox community, which constitutes approximately $15 \%$ of Israeli society, while the modern orthodox one deserves a separate study, since it considerably differs in its degree of openness.

\section{Methods}

Several ultra-orthodox newspapers, radio stations and other media, as well as adult and children's books were reviewed. In addition, members of the community were interviewed and various public announcements of religious leaders were analyzed, using qualitative research techniques, including in-depth content analysis.

\section{Findings and Discussion}

\section{Main Features of the Jewish Ultra-Orthodox}

Ultra-orthodox society may seem monolithic, but it actually comprises several subgroups with differing customs and varying degrees of openness to the modern world. Nonetheless, all these groups have much in common and have responded similarly to the threats of modern society and the new media.

Ultra-orthodox society in Israel, described in detail by M. Friedman (1991), Zicherman and Kahaner (2012) and Zicherman (2014), is characterized by strict observance of Jewish commandments and deep faith in Divine Providence. Events in this world are directed from above, but all humans possess free will, namely the ability to choose between good or evil.

Ultra-orthodox society demands obedience to the Lord's earthly representatives, the rabbis, whose rulings carry much weight. Great importanceis attributed to the study of Jewish sacred texts, primarily the Talmud. From childhood, men are obligated to lifelong learning. In recent years, the strict adherence to religious precepts and greater stringency in daily practice, has sometimesled to extremism.

Ultra-orthodox society has retained the traditional division of roles between men and women, with men commanded to lifelong study of the Talmud and women responsible for the household. However, in recent decades significant changes have occurred, for example: ultra-orthodox women have become an important part of the work force in Israel and in many families they are the main breadwinners. Also, most writers of ultra-orthodox fiction books are women.

The deeply conservative, Ultra-orthodox society takes a very cautious view of the modern world. Innovations or expressions of modernity are thoroughly scrutinized and sometimes rejected. Consequently, certain forms of mass media that are prevalent in general Israeli society, such as Internet and i-phones, are prohibited by ultra-orthodox rabbis.

Ultra-orthodox society is a closed one by choice, in order to protect itself from enticing external influences. It often resides in segregated communities or settlements where it forms the vast majority, thus providing members with a clear sense of identity and social security. The ultraorthodox society maintains its own institutions: schools, medical assistance organizations, mutual aid societies, shops, restaurants, travel packages, newspapers, music, singers, theater and movies and even courts, where civil disputes are judged according to Jewish law.

A separate educational system inculcates the ultra-orthodox world view to the next generation. Separation of sexes begins very early. Boys and girls attend different schools, where they are geared towards their future roles. Girls acquire certain vocations andare guided to marriage and motherhood, while boys are directed towards the study of Talmud. 
The family is the main stay of ultra-orthodox society. Great emphasis is put on family life and family planning is largely avoided. Modesty is upheld as one of the highest virtues and both women and men are required to dress modestly, but not from head to toe. Married women cover their hair and fashionable wigs are common. The conservatism of this unique community is also expressed in the mode of dress. Certain sects retain their traditional dress to distinguish themselves from surrounding society.

Since contact between unrelated men and women is discouraged, young men and women lack opportunities for spontaneous acquaintance. Hence, couples are formally introduced by their parents or a professional matchmaker. Matches are based on similar background, sub-group affiliation, shared aspirations and financial compatibility, all of which are carefully verified prior to the couple's first date. Often the couple meets only several times before reaching a final decision.

After marriage many young men continue to study Jewish law, for years, in a higher rabbinical school, while the wife usually works to support the family, raises children, and runs the household. The husband is away most of the day, busy with his studies, which award him a very modest allowance or scholarship. To ease the burden, one is encouraged to be content with his lot, and a simple and basic lifestyle is idealized, as prescribed by the Sages.

\section{Barriers to Free Flow of Information and IT Use}

To counter external influences and prevent desertion of tradition and religion, ultra-orthodox society seeks to isolate itself from surrounding secular society and to achieve maximal cultural and social segregation. The purpose is to offer its members a genuine alternative to modern secular society and culture, which is regarded as hedonistic, permissive, and decadent.

Justly claiming that media cannot be neutral and that all literature carries some message, spiritual leaders insist that both adults and youngsters consume only media and literature upholding, promoting, and consistent with their values and lifestyle. These leaders strongly oppose, on ideological grounds, any use of 'secular' media, both printed and electronic, including children's books (Kaplan and Shtadler, 2009).

To avoid consumption of 'secular' media, including television and Internet, which are considered a serious spiritual threat, they have successfully developed their own sub-cultural media and recreation activities, separated from the mainstream cultural life in Israel.

Perhaps due to its unconstrained and encompassing nature, the Internet in particular is perceived as a very serious spiritual threat and is the object of heated condemnation and total rejection. Prominent rabbinical figures from all ultra-orthodox circles constantly warn of the spiritual hazards of the Internet. In public rallies the Internetis termed "today's major threat to the souls of the young generation."

Admittedly, such harsh admonitions may attest to the contrary; perhaps the rabbinical leadership does not expect total compliance to its prohibitions and fears the consequences of dissent. After all, obedience is voluntarily and the rabbis lack tangible means of enforcement, besides social pressure. This includes social and community pressure, fears of ruining their offspring's matchmaking prospects, or refused admission to certain schools.

Thus, it is possible to understand the rationale behind the objection to IT and to free flow of information in general. The ultra-orthodox community is well aware of the hazards of unrestricted information and has employed various measures to counter it.These measures have enabled them to "walk the tight rope", that is, to utilize most, or at least part, of the immense benefits offered by the new IT and media, without compromising their ideology and religious principles. 
Obviously, the ultra-orthodoxcannot completely isolate themselves from the surrounding society.Working people need the Internet to communicate by e-mail and for necessary information searches.Many jobs obligate the use of computers and cell-phones.Even those who are full-time learners often needcell-phones to contact family and friends, since most pay-phone booths around the country have already been removed.

So, the question arises: how does this unique community solve the discrepancies between principles and rabbinical prohibitions and the constraints of reality?

\section{Solutions Based on Compromise}

1. Due to public demand and to commercial reasons, all Israeli cellular companies offer a certain type, nicknamed the "Kosher"cell-phone, adapted to the demands of the ultraorthodox community. This device lacks the option of Internetconnection and subsequently, the option of surfing, texting, whatsapp, etc.

2. Home computers are non-existent in many ultra-orthodox families. Others purchase a mobile computer or laptop which is easier for parents to supervise. The vast majority are not connected to the Internet and the few that are install various filters provided by commercial servers. Others have limited Internet access, including e-mail messages, but not information searches.

3. Only filtered Internet may be used, limited to breadwinning work and only cell-phones without Internet may be used.

4. Developing 'Kosher' alternatives to the general media and culture: writing their own books and producing their own movies and plays, all geared and adapted to the norms accepted among the ultra-orthodox community and approved by their rabbis.

As far as books are concerned, there is enormous ongoing demand for books and magazines. The demographic reality of large families resulted in a vast population of young book consumers, for whom reading has to replace television, computer, Internet etc. (Segev, 2003).

While the general Israeli population spends about one-third of its leisure time watching TV, and another third on Internet surfing, the ultra-orthodox sector is totally different in this respect as detailed above. The vast majority avoid television and in principle do not own one. The relatively few possessing home computers are not connected to the Internet. Consequently, reading remains one of the main leisure activities, thus creating a constant demand for books, magazines and newspapers.

Another result, publishing has become an important economic branch in this sector, annually producing thousands of titles of all genres: novels, thrillers, etc., intended for youngsters, women, and also men. Publishing became as important as the branches of food, clothing and toys.

\section{Conclusions}

1. Most of the described above is typical of a conservative and traditional society. Scholars of comparative religion can probably find parallels to other traditional societies, such as the Puritans in the past and perhaps the Amish today.

2. Sociologically, such behavior can be considered one means by which a religious-cultural minority seeks to conserve a specific sub-culture that advocates maximal separation from general secular culture.

3. Specifically regarding IT, the ultra-orthodox community insists on adhering to tradition, in order to retain its youngsters within the community and avoid large-scale desertions. 
4. It has been shown, however, that "solutions based on compromise" have been effective ways to address the "digital divide" problem of such ultra-conservative groups in order to improve performance of their members in modern societies.

5. IT is utilizedin this community in daily life, but with very clear-cut limits, such as various degrees of filtering and partial access to the Internet and other forms of IT. To be sure, these practical solutions block to a certain extent the free flow of information and knowledge. However, the ultra-orthodox community has been ready to pay this price in order to conserve its old traditions.

6. Without doubt, the voluntary segregation of this community takes its toll by reducing their involvement in important areas of life in modern society, like academy, higher education professions, army service, etc. The exclusion of so-called "secular studies" (e.g., Math, English, Physics, Chemistry, etc.) from the curriculum of most ultra-orthodox boys between the ages of 14 and 18, makes it almost impossible for them to later attend academic studies in higher education institutions. As a result, in a later phase of their life, when they marry and have to find a good high-income job, their options are very limited and many of them are forced to hold only low salary jobs, which do not require higher education background. It is a loss for them personally as well as to the whole country on the macro level.

\section{References and Other Resources}

Friedman, Menahem (1991). The ultra-orthodox society: sources, trends and processes. Jerusalem, The Jerusalem Institute for the study of Israel.

Gill,Grandon (2013).“Culture, complexity, and informing: how shared believes can enhanced our search for fitness", Informing Science: The International Journal of Emerging Transdiscipline, 16.

Hovav, Lea. (1994). "Ultra-orthodox children literature - realistic or didactic?",Sifrut Yeladim ve-Noar 20 (3-4), pp. 20-35. (in Hebrew)

Kaplan, K. and Shtadler, N. (2009).Leadership and authority in the ultra-orthodox society in IsraelChallenges and Alternatives. Jerusalem, Van-Leer Institute.(in Hebrew).

Regev, Menahem (2002). Children literature - reflections of society, ideology and values in Israeli children literature.Tel-Aviv, Ofir. (in Hebrew).

Segev, Y. (2009). Literature as creating and reflecting a narrative: the national-religious children literature as a test-case. Talelei Orot; Annual of Orot Yisrael College, 15, 229-242.(in Hebrew)

Segev, Y. (2003). Themes and trends in the ultra-orthodox and religious children literature from the 1990's on. Oreshet, 4 327-355.(in Hebrew)

Stadler, N., Lomsky F. E. \& Ben Ari, E. (2011).Fundamentalist Citizenships: the Haredi Challenge. In: G. Ben-Porat \& B. S. Turner (eds), The contradictions of Israeli citizenship: land, religion, and state. Milton Park, Abingdon, Oxon, [England] : Routledge

Yafe, Orit (2001). "Psychological aspects of Ultra-orthodox children literature: child and self concepts", Megamot 41 (1-2), pp. 10-19. (in Hebrew)

Yitzhaki, Moshe (1998), "Censorship in high school libraries in Israel: an exploratory field study", in: Education for All ; Culture, Reading and Information-Selected Papers from the Proceedings of the 27th Annual Conference of the International Association of School Librarianship.Ramat-Gan, IASL, pp. 265-275.

Yitzhaki, Moshe (2001). "Censorship in high school libraries in Israel: the role of the sectorial affiliation factor; an extended nation-wide field study", in: Inspiring Connections: Learning, Libraries and Literacy; Selected Papers from the Fifth International Forum on Research in School Librarianship (eds. P. Hughes and L. Selby). Seattle (Wash.),IASL, pp. 231-247. 
Yitzhaki, Moshe and Sharabi, Yosef (2005).“Censorship in Israeli high school libraries; analysis of complaints and librarians' reactions", in: Information Leadership in a Culture of Change;Selected Papers from the Ninth International Forum on Research in School Librarianship (eds. S. Lee a.o.). Hong Kong, IASL, pp. 183-202.

Zicherman, Haim and Kahaner, L. (2012).Modern ultra-orthodox - a Hareidi middle-class in Israel.Jerusalem, Israel Institute for Democracy. (in Hebrew)

Zicherman, Haim (2014). Black blue-white: a journey into the ultra-orthodox society in Israel.Tel-Aviv, 360 p. (in Hebrew).

\section{Biography}

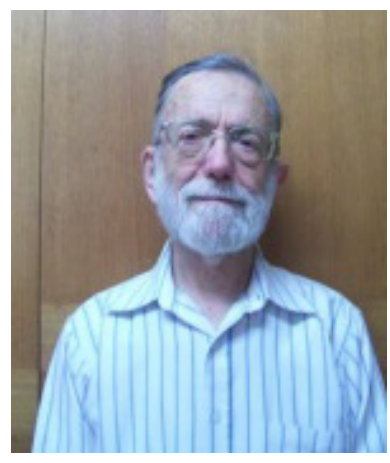

Moshe Yitzhaki was born in Israel in 1940. He did his undergraduate studies at Bar-Ilan University (economics and biblical studies) and masters degree in biblical studies there. MLS and PhD studies in Information and Library studies at Rutgers University, New Jersey, USA.

From 1980 he held a full-time position at Bar-Ilan Department of Information studies and director of the Jewish Studies Library. Senior lecturer (1988) and Associate Professor (2006). He retired 2009.

Research areas: information science, bibliometrics, Informatics, ultraorthodox children literature. 